\title{
Research on high density SMT reliability of aerospace products
}

\author{
Xuming Liu, Baiyang Cao, Yin Xu, Ran Xiao, Hailong Zhao \\ Tianjin Long March Launch Vehicle Manufacturing Co. Ltd, Tianjin, China \\ *|xm901202@163.com
}

\section{Key Words: high density; aerospace products; BGA; reliability}

\begin{abstract}
High density assembly of aerospace electronics equipment is an important direction of research linking technology. Based on the experiment, the paper complete the solder of high density aerospace products under different welding parameters, including PBGA and CBGA in different sizes. Secondly, execute the PCB board to thermal cycle test and vibration test which was welded under different process parameters, and finally through the Metallurgical Microscopy and scanning electron microscope finished the analysis.

In the experimental results, found that it contribute to the formation of $\mathrm{Cu} / \mathrm{Sn}$ alloy if the peak temperature value is higher than $220{ }^{\circ} \mathrm{C}$ for at least two seconds. The form of $\mathrm{Cu} / \mathrm{Sn}$ alloy will improve the reliability of the solder joints.
\end{abstract}

\section{Introduction}

Surface mount technology is widely applied in the fields of electronic products which as a new generation of electronic technology. Whether civil communication, computer, medical electronics, automobiles, household appliances, or in the military aerospace and aviation, etc, are accompanied with SMT technology ${ }^{[1][2]}$. The modern electronic products are developed to the miniaturization, the network and multimedia direction, therefore, encapsulation also put forward higher requirements for electronic devices ${ }^{[3]}$. BGA encapsulation realized device small, lead many, and has excellent electric properties, etc. BGA solder balls are at the bottom of the device, in the process of welding, after tin ball melting,they can selfcorrect, and the Solder joints are more reliable, so BGA devices are more and more widely used.

As the aerospace products toward to the direction of high density, more function, high integration, more and more high integration chips which imported from abroad are BGA encapsulation. The application of BGA devices in aerospace products will be more and more widely ${ }^{[4]}$.

\section{The Temperature Parameter}

The heat capacity of BGA device is larger than the level of resistance and container parts, therefore in the process of temperature curve setting, we find that under the same temperature parameters, the rising rate and falling rate of bare plate welding temperature is bigger than the BGA device, while, the reflux time of BGA devices is relatively longer to the bare plates. But in the whole process of temperature curve measuring, the throb of bare pad is more serious than the BGA device, the peak of BGA device is lower than bare bonding pad. In order to make sure that, on the same PCB board, devices which have different thermal capacity meet the space flight standard at the same time, we need to constantly adjust the reflow furnace temperature, chain speed, air 
pressure. These three parameters coordinate with each other far as possible, to ensure the BGA device has a smaller gap with the lower thermal capacity devices.

In the process of controlling, we must confirm that the absolute value of the rising and falling slope, heat preservation time, reflux time, of the temperature curve, reflow peak must meet the aerospace standard in different heat capacity devices.

In view of the BTU reflow furnace used in aerospace products, Specific experimental parameters as shown in TABLE I, II.

TABLE I . Reflow time 50s

\begin{tabular}{|c|l|l|l|l|l|l|l|l|}
\hline $\begin{array}{c}\text { Temperature } \\
\text { Zone }\end{array}$ & 1 & 2 & 3 & 4 & 5 & 6 & 7 & 8 \\
\hline Temperature & 110 & 125 & 150 & 163 & 167 & 167 & 194 & 252 \\
\hline
\end{tabular}

wind pressure: $40 \quad 40 \quad 80 \quad 60$

TABLE II . reflow time $60 \mathrm{~S}$

\begin{tabular}{|c|l|l|l|l|l|l|l|l|}
\hline $\begin{array}{c}\text { Temperature } \\
\text { Zone }\end{array}$ & 1 & 2 & 3 & 4 & 5 & 6 & 7 & 8 \\
\hline Temperature & 110 & 125 & 150 & 165 & 165 & 170 & 185 & 290 \\
\hline
\end{tabular}

wind pressure: $40 \quad 40 \quad 60 \quad 0$

\section{The Technological Processer}

The experiment process as shown in Fig. 1.

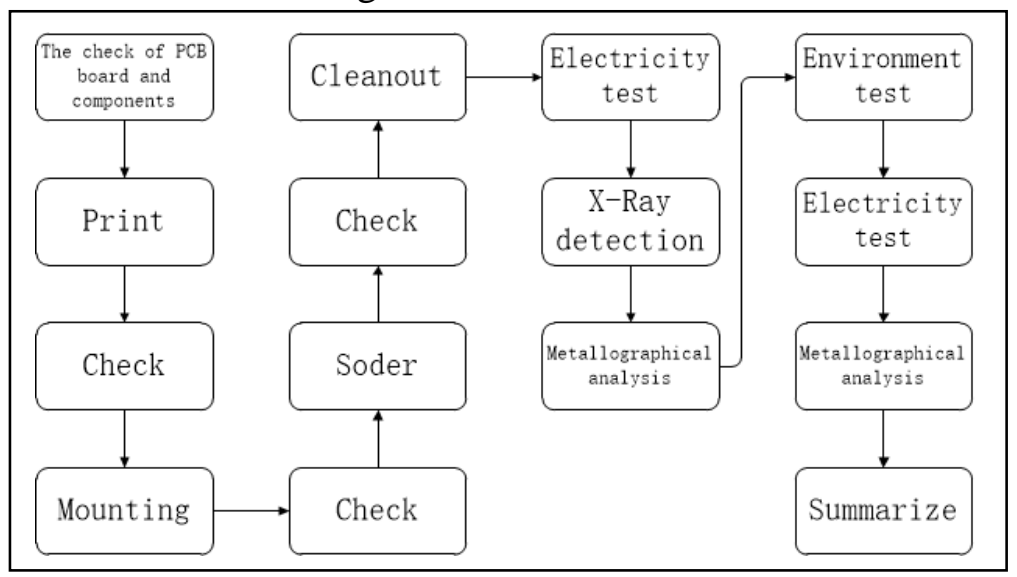

Figure 1. The experimental process

\section{A. SMT process}

SMT process as shown in Fig. 2.



Figure2. SMT technological process 


\section{B. Environmental test}

To test and verify the reliability of welding quality, put the welding finished PCB board to related environmental testing, including the thermal cycling test and vibration test.

- The thermal cycle test

Reference to the standard of China academy and space technology institute, IPC9701 and MILSTD883, set temperature range between $55^{\circ} \mathrm{C} \sim 100^{\circ} \mathrm{C}$, high and low temperature maintained at least $15 \mathrm{~min}$, temperature change rate is less than $10^{\circ} \mathrm{C} / \mathrm{min}$, each loop $1 \mathrm{~h}, 500$ cycles.

Test samples boards are doing preliminary drying in the temperature of $60^{\circ} \mathrm{C} \sim 80^{\circ} \mathrm{C}$ about $1 \mathrm{~h}$ before temperature cycling. Make electric test and organization structure analysis, at the end of circulation of the 200th, 300th, 400th, 500th of the BGA devices.

- The vibration test

According to aerospace products vibration test standards to do the related vibration test. The condition is shown in TABLEIII- TABLEV.

TABLEIII. Sine vibration conditions

\begin{tabular}{|l|c|l|}
\hline \multirow{4}{*}{ Sinusoidal vibration } & Frequency Range & $10 \mathrm{~Hz} 2000 \mathrm{~Hz}$ \\
\cline { 2 - 3 } & Vibrational amplitude & $0.5 \mathrm{~g}(0-$ peak $)$ vibrational amplitude \\
\cline { 2 - 3 } & Scanning speed & $20 \mathrm{tc} / \mathrm{min}$ \\
\cline { 2 - 3 } & Direction & $\mathrm{X} 、 \mathrm{Y}, \mathrm{Z}$ \\
\hline
\end{tabular}

TABLEIV. Sine vibration minimum order of magnitude

\begin{tabular}{|c|c|l|l|}
\hline \multirow{4}{*}{$\begin{array}{c}\text { The minimum magnitude of sinusoidal } \\
\text { vibration }\end{array}$} & Frequency Range (Hz) & $25 \sim 100$ & $100 \sim 200$ \\
\cline { 2 - 4 } & PSD speed (O-peak) & $20 \mathrm{~g}$ & $15 \mathrm{~g}$ \\
\cline { 2 - 3 } & Scanning speed otc/min & 1 & \\
\cline { 2 - 3 } & Keep time: & $25 \mathrm{~Hz} 200 \mathrm{~Hz}$ onecycle \\
\hline
\end{tabular}

TABLEV . Random vibration minimum order of magnitude

\begin{tabular}{|c|c|c|c|c|c|c|c|}
\hline \multirow{4}{*}{$\begin{array}{l}\text { The minimum } \\
\text { level of } \\
\text { random } \\
\text { vibration }\end{array}$} & \multirow{2}{*}{$\begin{array}{l}\text { Vertical } \\
\text { of PCB }\end{array}$} & $\begin{array}{c}\text { Frequency } \\
\text { Range }(\mathrm{Hz})\end{array}$ & $20 \sim 100$ & $100 \sim 500$ & $500 \sim 2000$ & \multirow[t]{2}{*}{$28.5 \mathrm{~g} \mathrm{~ms}$} & \multirow{4}{*}{$\begin{array}{l}\text { Keep time : } \\
5 \mathrm{~min} \text { in every } \\
\text { direction }\end{array}$} \\
\hline & & PSD level & $6 \mathrm{~dB} / \mathrm{oct}$ & $1.0 \mathrm{~g} 2 / \mathrm{Hz}$ & $-6 \mathrm{~dB} / \mathrm{oct}$ & & \\
\hline & \multirow{2}{*}{$\begin{array}{l}\text { Parallel } \\
\text { of PCB }\end{array}$} & $\begin{array}{c}\text { Frequency } \\
\text { Range }(\mathrm{Hz})\end{array}$ & $20 \sim 100$ & $100 \sim 800$ & $800 \sim 2000$ & \multirow[t]{2}{*}{$27.1 \mathrm{~g} \mathrm{~ms}$} & \\
\hline & & PSD level & $6 \mathrm{~dB} / \mathrm{oct}$ & $0.5 \mathrm{~g} 2 / \mathrm{Hz}$ & $-3 \mathrm{~dB} / \mathrm{oct}$ & & \\
\hline
\end{tabular}

\section{Detection and analys is of organization}

Respectively make electric test, X-Ray test, metallographic organization and energy spectrum analysis of the welding complete board.

- The electric test

The electric test all performance well before the environmental test, in the temperature cycle of 200 times, 300 times, 400 times,500 times , PBGA didn't appear failure. But the CBGA devices which welding reflux time is $50 \mathrm{~s}$, the peak between $210{ }^{\circ} \mathrm{C}$ and $220{ }^{\circ} \mathrm{C}$, and the solder points less than 625 pin, failure rate reached $50 \%$ after 200 cycles and the number of 256 pins CBGA failure rate was $30 \%$. In the end of 300th temperature cycle, all 625 pins CBGA has losed, 256 pins 
CBGA failure rate reached $80 \%$. The temperature curve peak value appeared in more than $220{ }^{\circ} \mathrm{C}$, the CBGA solder joints didn't appear any failure .

- X-Ray detection

Only find some small size hole In the welded BGA devices, and other defects was not observed. As was shown in Fig. 3.

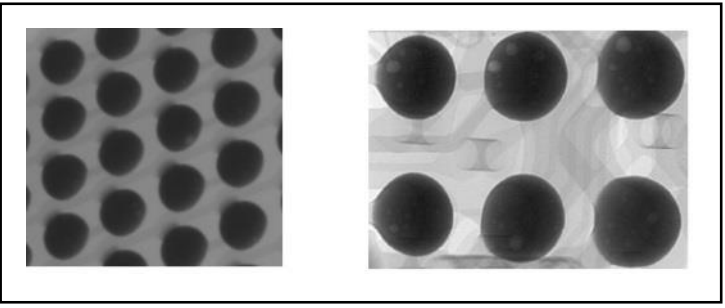

Figure 3. small hole of solder joints

- The metallographic and analysis before and after the experiment environment

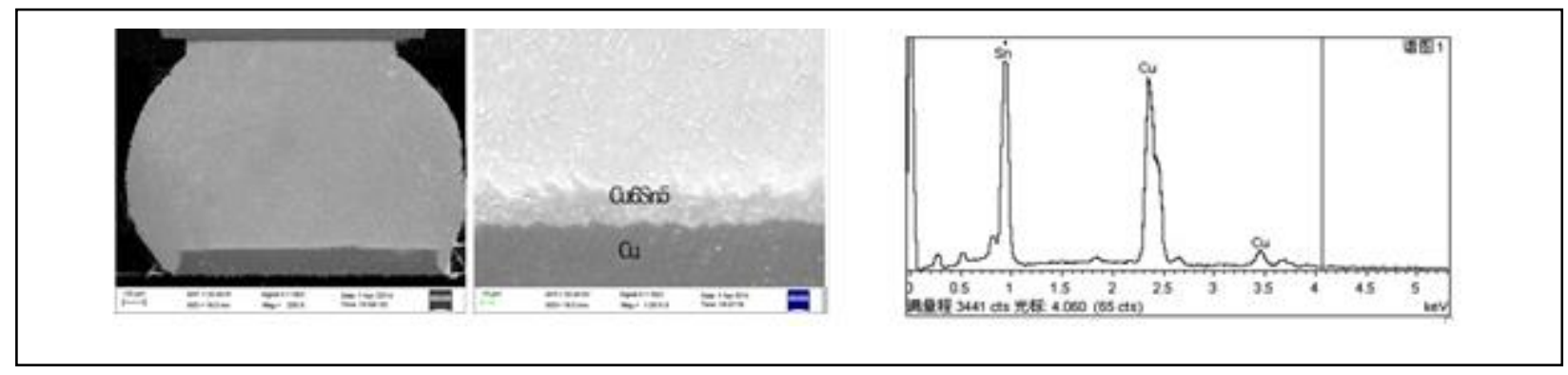

Figure 4. The PBGA scanning electron micro scope and energy spectrum picture before environment

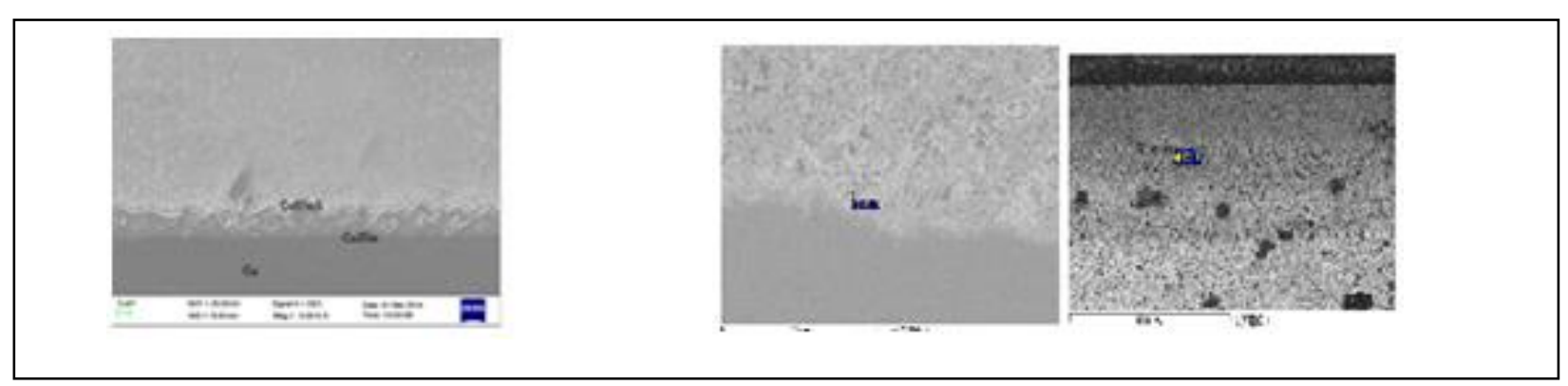

Figure 5. The pick value is higher and lower than $220^{\circ} \mathrm{C}$ of CBGA

Under different technological parameters of different packaging sizes of BGA, the solder joints metallographic figures and the corresponding EDX analysis diagram can be seen that the PBGA solder joints and the reflux peak value at $220{ }^{\circ} \mathrm{C}$ in 60 s of CBGA solder joints are formed the Cu6Sn5 alloy layer, and distributed very evenly. CBGA solders which reflow peak value is lower than $220{ }^{\circ} \mathrm{C}$, is not form obvious $\mathrm{Cu} / \mathrm{Sn}$ crystal layer between the pad and solder ball, and did not produce any metallic bond, there is not corresponding compounds. The spectrum analysis diagrams after environment test are as follows: 


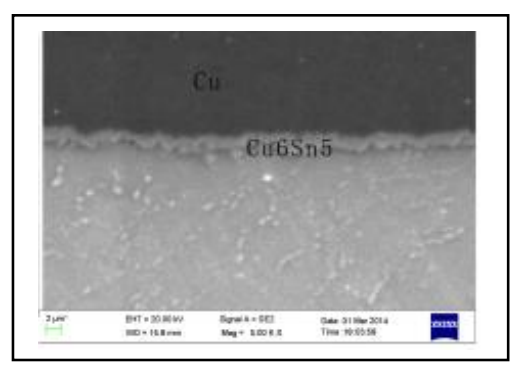

Figure 6. solder points SEM figure of PBGA

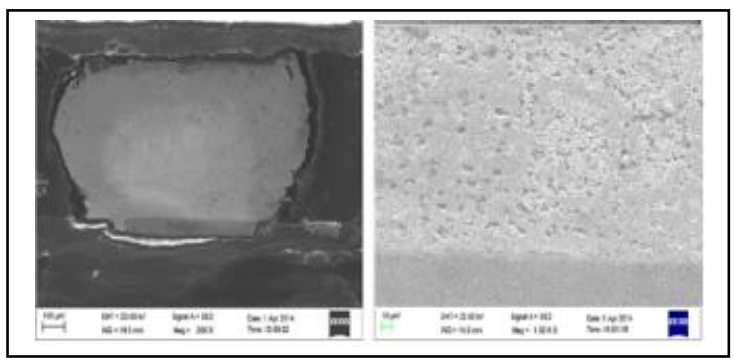

Figure 7. reflux peak value at $210^{\circ} \mathrm{C}$ SEM figure of CBGA

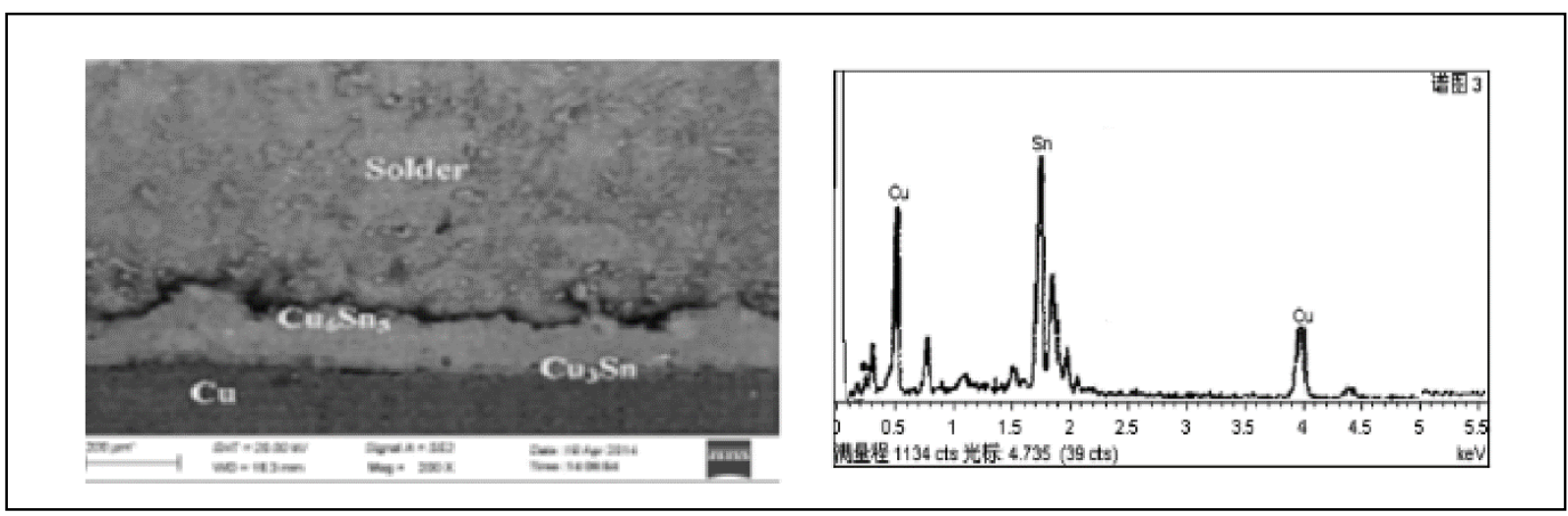

Figure 8. reflux peak value higher than $220^{\circ} \mathrm{C}$ SEM figure of CBGA

By the different process parameters of different sizes and different packaging of BGA devices after environmental testing metallographic images, SEM and EDX images, it can be seen that solder joints of CBGA components, reflowing peak value lower than $220{ }^{\circ} \mathrm{C}$ has been broken in the root, and the curve peak value higher than $220{ }^{\circ} \mathrm{C}$, the CBGA solder joints didn't fracture, has good electric properties, and alloy layer has the obvious change, the $\mathrm{Cu}$ layer, $\mathrm{Sn}$ layer, rich $\mathrm{Pb}$ layer, $\mathrm{Sn} / \mathrm{Pb}$ layer are all changed .

Compared to original state without environmental testing metallographic and SEM figures, can find that the $\mathrm{Cu}$ layer, $\mathrm{Cu} / \mathrm{Sn}$ layer, $\mathrm{Sn} / \mathrm{Pb}$ layer all has changed significantly.

After environmental testing, the CBGA components with lower welding peak value, didn't form metallic bond, that is to say no corresponding Cu6Sn5 compound formation. Which, after environment test, result in high failure rate. Formation of $\mathrm{Cu6Sn} 5$ alloy layer of solder joints, no failure after environmental testing. By comparing, it will be found that the form of Cu6Sn5 alloy layer in the welding process is vital to ensure the solder joint reliability. Cu3Sn phase appeared in the Cu6Sn5 alloy layer after environmental testing.

It will form different thickness metal alloy layer under different reflux time. By the experimental results can be concluded that, BGA solder joint alloy layer in the parameters of reflow time longer is obviously thicker than the reflux time shorter one. The formation of Cu3Sn compounds make alloy layer's thickness increases, and lead to solder brittle after environmental testing .

In fact, the born of IMC between the solder and solder composition are two stages, the first stage is in the process of welding, IMC was formed between $\mathrm{Sn} / \mathrm{Pb}$ solder and $\mathrm{Cu}$ substrate; The second stage is after completion of the welding, in the process the environment test, IMC was formed between $\mathrm{Cu}$ pad and solid solder.

In the welding process, when the $\mathrm{Cu}$ contact with the liquid $\mathrm{Sn} / \mathrm{Pb}$ solder, $\mathrm{Cu}$ began to dissolve in the solder liquid, so between the $\mathrm{Cu}$ pad and liquid of $\mathrm{Sn} / \mathrm{Pb}$ solder will form a saturated layer of 
$\mathrm{Cu}$. Despite the metastable super saturation, but when $\mathrm{Cu}$ dissolution has reached the local equilibrium, IMC (Cu6Sn5) will be form there. The formation of intermetallic compound consumes $\mathrm{Cu}$ in the saturation state of liquid solder, resulting in a further dissolution of $\mathrm{Cu}$ pad to liquid solder. As the crystallization and interconnection of Cu6Sn5, it formed a continuous layer of IMC layer between $\mathrm{Cu}$ pad and solder interface, the continuous IMC layer restraint $\mathrm{Cu}$ on pad dissolved further to liquid solder. In the solid state environmental testing, Cu3Sn is formed at the request of the thermodynamic equilibrium condition. This means that the IMC between the $\mathrm{Cu}$ pad and $\mathrm{Cu} 6 \mathrm{Sn} 5$ is an unstable interface, once the temperature is enough to activate the reaction of $\mathrm{Cu}$ and $\mathrm{Sn}$ atoms, in $\mathrm{Cu}$ pad and $\mathrm{Cu} 6 \mathrm{Sn} 5$ intermetallic compound layer interface, will depend on the solid phase diffusion form Cu3Sn intermetallic compounds. Since then, the diffusion of $\mathrm{Cu}$ and Sn still continue, which is main $\mathrm{Cu}$ through $\mathrm{Cu} 3 \mathrm{Sn}$ and $\mathrm{Cu} 6 \mathrm{Sn} 5$ intermetallic layer spreading in the solder. When $\mathrm{Cu}$ spread and resided in $\mathrm{Cu} 3 \mathrm{Sn} / \mathrm{Cu} 6 \mathrm{Sn} 5$ interface and $\mathrm{Cu} 6 \mathrm{Sn} 5$ solid solder interface, which create these two kinds of IMC growth to the solder.

\section{Conclusion}

The main research results can be summarized as the following:

A. The analysis of the effect of temperature curve for different encapsulation BGA devices

B. The solder joint reliability of environmental testing verification

C. Do energy spectrum analysis of the solder joints which were welded in different temperature curve, before and after environmental testing

Control the flow curve reasonably is helpful to control the thickness of the solder alloy layer, and the peak value of the temperature curve is higher than $220^{\circ} \mathrm{C}$ or more for at least two seconds is helpful to form $\mathrm{Cu} / \mathrm{Sn}$ alloy, the formation of $\mathrm{Cu} / \mathrm{Sn}$ alloy will help to improve the reliability of solder joints.

The optimized parameters is based on the existing engineering environment, production equipment and testing equipment of the Aerospace Institute, it can meet the demand of the reliability of the high density aerospace products, but whether the process parameters to be optimized in more worse environment, different engineering environment, is still need further study.

\section{Reference}

[1] Andy C maceie. Reflow atmospheres in the lead [J]. Circuits assembly ,2003, (3): 26 - 35 .

[2] Adams J.A. 'Using Cross. Sectional X-Ray Techniques for Testing Ball Grid Array Connections and Improving Process Quality”, Proceedings Nepcon Weat, 1994.

[3] Kaiyun $\mathrm{Gu}$, etc. Bad fault of SMT reflow welding (welding defects) analysis and prevention countermeasures [C]. " Beijing international SMT technology exchange meeting, 2002.

[4] Baiyang Cao, etc. The application and development of surface mount technology [J]. "Journal of north China institute of aerospace industry", 2003.

[5] Lun Zhang, etc, translate. Martin P.L. The first edition of electronic failure analysis manual. Beijing: Science Press, 2005.

[6] Wengong Luo. BGA encapsulation of thermal stress analysis and reliability research [D]. p10. 2009. 